\title{
ОСОБЕННОСТИ ОРГАНИЗАЦИИ ВНУТРЕННЕГО КОНТРОЛЯ В ГОСУДАРСТВЕННЫХ УНИТАРНЫХ ПРЕДПРИЯТИЯХ
}

\author{
() 2020 Петров А. M. \\ доктор экономических наук, профессор Департамента учета, анализа и аудита \\ Финансовый университет при Правительстве Российской Федерации, Россия, Москва \\ E-mail:palmi@inbox.ru \\ (c) 2020 Мельникова Л. А. \\ кандидат экономических наук, доцент Департамента учета, анализа и аудита \\ Финансовый университет при Правительстве Российской Федерации, Россия, Москва \\ E-mail:lamelnikova@mail.ru
}

Внутренний контроль представляет собой систему мероприятий, которая позволяет своевременно выявлять недостатки в работе подразделений и причины их образования, а также мотивировать сотрудников предприятия на добросовестное выполнение своих должностных обязанностей. Кроме того, благодаря внутреннему контролю своевременно выявляются недостатки, скрытые резервы и риски, которым подвержено предприятие, и на основании полученных заключений проводятся необходимые мероприятия для совершенствования деятельности и ограничения рисков деятельности государственных унитарных предприятий.

Ключевые слова: задачи, инструментарий, контроль, кризисные ситуации, механизмы, подходы, проекты, расходы, реализация, средства, финансы, экономическая информация, эффективность.

На экономические субъекты, «бухгалтерская (финансовая) отчетность которого подлежит обязательному аудиту», согласно Закону № 402Ф3 «О бухгалтерском учете» возложена обязанность по организации и функционированию внутреннего контроля. Так как государственные унитарные предприятия согласно Закону от 30.12.2008 г. № 307-Ф3 «Об аудиторской деятельности» подлежат обязательному аудиту, то норма по ведению внутреннего контроля закрепляется законодательно и носит обязательный характер.

На данный момент не существует нормативных актов или методических рекомендаций, регламентирующих, в какой форме и объеме должна функционировать система внутреннего контроля предприятия. Согласно Постановлению Правительства Российской Федерации от 30 июня 2012 г. № 667 (ред. от 11.09.2018) «Об утверждении требований к правилам Внутреннего контроля, разрабатываемого организациями, осуществляющими операции с денежными средствами или иным имуществом (за исключением кредитных организаций)» правила внутреннего контроля утверждаются руководителем организации и предусматривают особые правила проверки ведения внутреннего контроля.

В современных условиях внутренний конт- роль становится одним из важнейших элементов эффективного управления организацией. Поэтому совершенствование деятельности службы внутреннего контроля в соответствии с последними законодательными тенденциями является государственных унитарных предприятий одним из приоритетных направлений. За последнее время на этих предприятиях имеют место кардинальные перестройки организационных структур, а также системы внутреннего контроля, направленные на своевременное выявление и оценку потенциальных рисков, осуществление превентивных мер для минимизации вероятности наступления событий, способных нарушить нормальное функционирование предприятия.

По решению и в интересах органов управления в организации могут создаваться специализированные подразделения внутреннего контроля. Такое подразделение может подчиняться не только руководителю предприятия, но и его собственнику. Собственник проводит внутренние внеплановые проверки деятельности предприятия, как правило, силами собственной контрольно-ревизионной службы, которая фокусируется на вопросах проверки сохранности товарно-материальных ценностей, эффективности использования ресурсов, выполнения распоряжений вышестоящих органов, а также на расследовании случаев мошенничества. В ходе 
проверки также рассматривается характер расчетов по договорам с контрагентами с позиции экономических интересов предприятия.

Как видно из представленной на рис. 1 схемы, обособленное подразделение службы внутреннего контроля на предприятии отсутствует. Однако данный факт совсем не означает, что имеющиеся на предприятии органы внутреннего контроля неэффективны. Рассмотрим их функции более подробно.

\section{Бухгалтерская служба:}

Основной целью службы внутреннего контроля в отношении работы бухгалтерского подразделения является:

- регулярный контроль за финансовохозяйственной деятельностью предприятия и его филиалов

- проверка полноты, достоверности и точности отражения в учете и отчетности затрат, доходов и результатов финансовой деятельности филиалов

- проверка наличия, состояния и обеспечения сохранности имущества предприятия

- контроль за расчетно-платежной дисциплиной

- контроль за сохранностью активов организации

- проведение контроля по вопросам соблюдения положений по учетной политике для целей бухгалтерского и налогового учета, исполнения норм законодательства Российской Федерации и внутренних локально-нормативных актов.

- обучение сотрудников бухгалтерской службы

Внутренний контроль процесса производства

- проверка полноты выполнения плановых показателей, исполнения заданий по объему производства, уровню затрат на производство работ и оказание услуг, прибыли и платежам в бюджет

- выявление резервов в области повышения эффективности использования материальных, трудовых и денежных ресурсов, технологического оборудования с учетом внедрения в производство нового оборудования и технологических достижений, принимаемых мер по мобилизации внутрихозяйственных резервов, устранению непроизводственных потерь и расходов

- контроль соблюдения коллективного договора, трудового законодательства, условий ведения трудовой деятельности

Управление экономической безопасности:

- обеспечение недопущения утечки инсайдерской информации, коммерческих планов и информации, представляющей собой коммерческую тайну.

- поиск конкурирующих организаций, созданных сотрудниками предприятия, а также отслеживание взаимодействия и деловых контактов между сотрудниками и представителями конкурирующих предприятий

Управление оперативно-служебного контроля

- оценка рисков при работе с контрагентами

На предприятии имеется утвержденный генеральным директором «Регламент проверки контрагентов», который устанавливает критерии оценки контрагентов на предмет наличия предпринимательских и налоговых рисков, а также порядок проверки контрагентов на стадии заключения и исполнения договоров, а так-

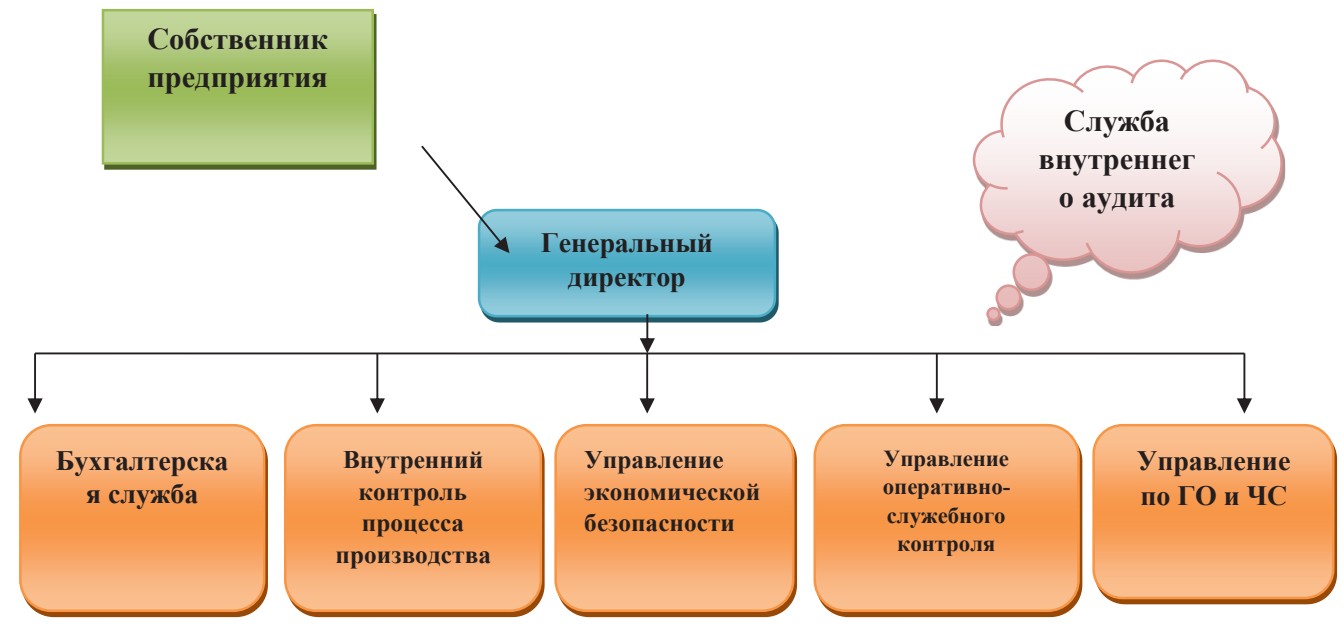

Puc. 1. Типовая схема построения внутреннего контроля в государственных унитарных предприятиях 
же в последующем обнаружения предприятием признаков, которые могут повлечь признание налоговым органом возникновения у предприятия необоснованной налоговой выгоды вследствие отражения этим налогоплательщиком в его бухгалтерской и налоговой отчетности экономических результатов сделок с контрагентами, имеющими признаки недобросовестных налогоплательщиков.

Основной риск взаимодействия с заказчиком по договорам заключается в том, что Заказчик не оплатит выполненные работы или оплатит несвоевременно. Таким образом, основной риск - это риск возникновения дебиторской задолженности - просроченной, либо сомнительной.

Для оценки степени риска возникновения дебиторской задолженности выясняется, имелись ли такие факты во взаимоотношениях с Заказчиком в прошлом.

В случае, когда заключается договор с новым Контрагентом, оценка степени риска возникновения дебиторской задолженности осуществляется на основании следующих данных:

1) реестр недобросовестных поставщиков;

2) участие в судебных спорах;

3) запрос финансовой отчетности, заверенной налоговым органом.

Практически по всем договорам существует риск возникновения дебиторской задолженности. В любом случае, для минимизации риска возникновения дебиторской задолженности с такими Заказчиками упор делается на то, чтобы четко прописать в условиях договора штрафные санкции в случае несвоевременной оплаты.

- проверка благонадежности и добропорядочности сотрудников, физических лиц контрагентов и контрагентов

- контроль исполнения приказов, распределение и делегирование ключевых полномочий и ответственности, обеспечение эффективного взаимодействия структурных подразделений и сотрудников предприятия

- проверка и экспертиза договоров на предмет выявления признаков умысла, фиктивности и мошенничества, а также выявление и предотвращение налоговых, административных, уголовных рисков и рейдерских угроз.

- обеспечение информационной безопасности, сохранения тайны переписки, авторских прав и коммерческой тайны при работе в условиях электронной коммерции: превентивные мероприятия по установке антивирусных про- грамм, использование технологий шифрования, применение систем аутентификации пользователя посредством электронно-цифровой подписи, а также недопущение несанкционированного проникновения в незащищенные сети.

Предприятие устанавливает порядок защиты от несанкционированного доступа и распространения конфиденциальной информации, а также от использования конфиденциальной информации в личных целях.

\section{Управление по ГО и ЧС}

На предприятии имеется утвержденное генеральным директором «Положение об аварийноспасательной службе предприятия» и другие положения, регламентирующие действия сотрудников в случае чрезвычайных ситуаций.

В условиях повседневного функционирования предприятия проводятся такие превентивные мероприятия, как заключение договоров с резервными провайдерами, договоров на дублирующую телефонную связь, резервное копирование баз данных, обеспечение ресурсов на случай чрезвычайной ситуации и контроль за деятельностью аварийно-спасательной службы, а также организация служебных расследований по различным чрезвычайным происшествиям и обстоятельствам.

На предприятии успешно функционирует плановый и внеплановый контроль. При комплексной плановой проверке составляется график ее проведения, который составляется в начале года и своевременно и оперативно доводится до руководителей филиалов. В него включаются участки учета, подлежащие проверке, начальные и конечные даты ее проведения, срок написания отчета по проверке, ответственные лица за ее проведение, методы проверки. График доводится до всех заинтересованных лиц.

Результатом внутреннего контроля является акт, в котором достоверно отражаются факты проведенной проверки в части финансово-хозяйственной и производственной деятельности филиалов.

При внеплановых проверках контролируются участки учета, в отношении которых есть информация о возможных нарушениях и злоупотреблениях. Инициируется такая проверка, как правило, Приказом руководителя организации, с указанием предпосылок проведения внеплановой проверки.

Таким образом, все указанные службы в совокупности и каждая в частности обеспечивают бесперебойное функционирование системы 
внутреннего контроля предприятия, все сотрудники указанных служб обладают обширными профессиональными знаниями и хорошо ориентируются в бухгалтерском, налоговом, гражданском, уголовном и трудовом законодательствах. Сотрудники постоянно поддерживают высокий уровень своих профессиональных навыков и умений, своевременно проходят обучение и аттестацию.

Однако, по мнению руководства предприятия, для совершенствования работы существующей службы внутреннего контроля необходимо учитывать современные тенденции в организации службы внутреннего контроля в крупнейших российских и зарубежных компаниях. Одной из приоритетных задач является создание собственной службы внутреннего аудита. Нормативные документы в отношении внешнего обязательного аудита возможно применить и к организации внутренних контрольных мероприятий.

Функции службы внутреннего аудита включают мониторинг адекватности и эффективности системы внутреннего контроля, ведь от внутреннего контроля собственники и руководство предприятия могут ожидать только обоснованного уровня обеспечения достижения постав- ленных целей, но никак не абсолютной гарантии безошибочной работы.

Процесс внутреннего аудита является сложной и многоуровневой процедурой, выполняется обособленной независимой службой и, согласно профессиональным стандартам, выработанными международным Институтом внутренних аудиторов, именно профессиональные внутренние аудиторы играют ключевую роль в оценке и гарантировании эффективности систем контроля и управления. Поэтому для ГУП, которое нацелено на дальнейшее развитие и повышение эффективности своей деятельности, создание такой службы поможет усовершенствовать существующую систему внутреннего контроля, а также получить дополнительные конкурентные преимущества, снизить предпринимательские риски, стать более привлекательным для потенциальных заказчиков, а также поможет демонстрировать более высокие финансовые показатели и стабильность. Ведь залогом ведения успешного бизнеса является наличие эффективной системы управления: не будет системы - не будет и порядка. Поэтому работа над созданием службы внутреннего аудита уже ведется и ее внедрение не заставит себя долго ждать.

\section{Библиографический список}

1. Информация Минфина России № П3-11/2013 «Организация и осуществление экономическим субъектом внутреннего контроля совершаемых фактов хозяйственной жизни, ведения бухгалтерского учета и составления бухгалтерской (финансовой) отчетности».

2. Бюджетный кодекс Российской Федерации от 31.07.1998 № 145-Ф3 (ред. от 27.12.2019 г.).

3. Бюджетный кодекс Российской Федерации от 31.07.1998 № 145-ФЗ (ред. от 27.12.2019 г.).

4. Угловный кодекс Российской Федерации от 13.06.1996 г. № 63-Ф3 (в ред. 18.02.2020 г.).

5. Кодекс Российской Федерации об административных правонарушениях от 30.12.2001 № 195 -ФЗ (в ред. от 18.02.2020).

6. Федеральный закон от 05.04.2013 г. № 44-Ф3 «О контрактной системе в сфере закупок товаров, работ, услуг для обеспечения государственных и муниципальных нужд» (в ред. от 27.12.2019 г.).

7. Федеральный закон от 26.07.2019 № 199-Ф3 «О внесении изменений в Бюджетный кодекс Российской Федерации в части совершенствования государственного (муниципального) финансового контроля, внутреннего финансового контроля и внутреннего финансового аудита».

8. Бабаев Ю.А., Друцкая М.В., Кеворкова Ж.А., ЛистопадЕ.Е., Петров А. М. Бухгалтерский учет, анализ и аудит внешнеэкономической деятельности / учебник для студентов обучающихся по специальности 080109 «Бухгалтерский учет, анализ и аудит» / под редакцией Ю.А. Бабаева. Москва, 2010.

9. Петров А.М., Мельникова Л.А. Теоретические аспекты учета калькулирования себестоимости продукции / Экономические науки. 2013. № 102. С. 145-148.

10. Kevorkova Z.A., Petrov A. M., Savina N. V. Towards Liabilities Of Corporate Systems / International Journal of Civil Engineering and Technology. 2019. T. 10. № 2. C. 1582-1593.

11. Lymar M.P., Kevorkova Z.A., Petrov A.M. The Convergence Of National And International Accounting Standards: Chinese Experience / International Journal of Civil Engineering and Technology. 2018. Т. 9. № 13. C. 82-94.

12. Петров А.М., Коняхин А.Н. Учетная политика при подготовке первой отчетности согласно МСФО / Международный бухгалтерский учет. 2013. № 11 (257). С. 2-15. 